\title{
Stage I Nasal Cavity and Paranasal Sinus Cancer AJCC v8
}

National Cancer Institute

\section{Source}

National Cancer Institute. Stage I Nasal Cavity and Paranasal Sinus Cancer A/CC v8. NCI

Thesaurus. Code C133076.

Stage I includes: T1, N0, M0. T1: Maxillary sinus: Tumor limited to the maxillary sinus mucosa with no erosion or destruction of bone. Nasal cavity and ethmoid sinus: Tumor restricted to any one subsite, with or without bony invasion. N0: No regional lymph node metastasis. M0: No distant metastasis. (AJCC 8th ed.) 